whole. Or he may simply be choosing the first card he sees, particularly when he has no strong feelings about one card being right-side up or is confused by the mirror-images that occur in the vertical array. The latter possibility would imply a more consistent scanning process vertically than horizontally. With either possibility, the occurrence of a bias in the vertical array but not in the horizontal array suggests again that the direction of scanning or comparison makes a difference to the young child's judgments, a point that unites Ghent Braine (Ghent, 1960; Braine, 1966), Sekuler \& Rosenblith (1964), and Huttenlocher (1967).

\section{REFERENCES}

ANTONOVSKY, H. F., \& GHENT, L. Cross cultural consistency of children's preferences for the orientation of figures. American Joumal of Psychology, 1964, 77, 295-297.

\title{
Visual and pronouncing responses in free recall learning
}

\author{
SHELDON G. KIRSHNER and L. BERELL \\ KORNREICH, University of Wisconsin, \\ Milwaukee, Wis. 53201
}

In two experiments the relative importance of pronouncing and visual responses during free-recall learning were compared. When overt pronouncing responses were required of both groups, the different amount of time available for visual responding had no effect. When Ss were not required to make overt pronouncing responses, the group which had less opportunity to make visual responses did significantly better. These results obtained with a different methodology supported previous work by Mechanic and his co-workers, who have stressed the importance of the pronouncing response and the relative unimportance of the visual response.

Mechanic \& D'Andrea (1966) raise an interesting and important question when they ask "whether $S$ can learn passively by the imprinting upon him of a sensory image or trace, or whether he has to make some response in order for learning to occur." In comparing a group of undergraduates told to rate the visual attractiveness of a number of trigrams and a similar group told to pronounce the same trigrams silently, they found significantly greater recall in the pronouncing group. It was concluded that little learning occurred as a result of "visual responses" when pronouncing responses were not made by $S$.
BRAINE, L. G. Age changes in the mode of perceiving geometric forms. Psychonomic Science, 1965, 2, 155-156.

GHENT, L. Form and its orientations: A child's eye view. American Journal of Psychology, $1961,12,95-101$

HUTTENLOCHER, J. Children's ability to order and orient objects. Child Development, 1967, 38, 1169-1176.

SEKULER, R. W., \& ROSENBLITH, J. F. Discrimination of direction of line and the effect of stimulus alignment. Psychonomic Science, 1964, 1, 143-144.

\section{NOTE}

1. Based on a Master's thesis by Carolyn Moeller, directed by Jacqueline Goodnow, with Goodnow's participation made possible by support from the National Institute for Child Health and Human Development (1K03-HD36791; 1R01-HD03105; and 2T01-HD00203). during the time when the screen was blank. Pronouncing responses (aloud) were required during the entire learning trial for the two groups. For two additional groups, there was no pronouncing requirement.

\section{EXPERIMENT 1} Subjects

The Ss were 40 undergraduate students enrolled in an introductory psychology course, who received credit for participating in experiments. Previous participation in a nonsense-syllable experiment disqualified Ss from the experiment.

Apparatus and Materials

The stimulus materials were 24 trigrams, with four each being rated at a $0 \%, 20 \%$, $40 \%, 60 \%, 80 \%$, and $100 \%$ level of meaningfulness (Hilgard, 1950). A Kodak Carousel projected the syllables onto a screen about $10 \mathrm{ft}$ away from $\mathrm{S}$. The same random order of stimulus presentation was used for all Ss, and each $S$ was run individually.

\section{Procedure}

Two groups which differed in only one respect, and each containing $20 \mathrm{Ss}$, were run. Group 1 was shown each stimulus for $15 \mathrm{sec}$ with a 1-sec ITI, while Group 2 was shown each stimulus for $6 \mathrm{sec}$, followed by a blank slide for $8 \mathrm{sec}$ which took $1 \mathrm{sec}$ to appear. The ITI was also $1 \mathrm{sec}$ for Group 2. Thus the only difference between the groups was that Group 1 received the stimulus visually 2.5 times as long as did Group 2. The groups had an equal amount of time to learn the stimuli.

The groups were told that they would see a number of nonsense syllables and that their task was to remember them so that they could write them down in any order. Both groups were instructed to say each syllable out loud "at a rate and in a tone" that was comfortable for them, and to keep repeating it from the time that it came on until the next syllable appeared. Additional instructions were given to Group 2 which explained the blank slide procedure and emphasized the importance of continued pronouncing aloud throughout the entire trial, even during the time when the stimulus slide was changed to a blank slide.

The retention test was identical for both groups. A free-recall test of $190 \mathrm{sec}$ was administered by having Ss write down in any order as many of the nonsense syllables as they could remember. They were told that incorrect answers did not count against them. After their answer sheets were collected, Ss were asked what they had done to remember the syllable during the time the stimulus was being presented. In addition, Group 2 Ss were asked what they had done during the time the blank slide was being presented to remember the nonsense syllables.

For a second group, the stim only briefly presented, followed by a blank screen during the remaining learning trial. Thus the availability of the stimulus for making visual responses was eliminated

\section{Results} Group 1 was 9.05 , as compared with 8.25
The mean number of stimuli recalled by 
Table 1

Mean number of stimuli recalled as a function of pronouncing requirement and stimulus exposure time

\begin{tabular}{|c|c|c|}
\hline $\begin{array}{l}\text { Experiment } 1 \\
\text { (Ss pronounced aloud }\end{array}$ & Mean & SD \\
\hline $\begin{array}{l}\text { (Long Exposure) Group } 1 \\
\text { (Short Exposure) Group } 2\end{array}$ & $\begin{array}{l}9.05 \\
8.25\end{array}$ & $\begin{array}{l}2.10 \\
1.21\end{array}$ \\
\hline \multicolumn{3}{|l|}{$\begin{array}{l}\text { Experiment } 2 \\
\text { (Ss did not pronounce aloud) }\end{array}$} \\
\hline $\begin{array}{l}\text { (Long Exposure) Group } 3 \\
\text { (Short Exposure) Group } 4\end{array}$ & $\begin{array}{r}8.10 \\
10.45\end{array}$ & $\begin{array}{l}3.35 \\
3.48\end{array}$ \\
\hline
\end{tabular}

for Group 2. A test of significance for these means revealed no significant difference $[t(1,38)=1.43, p>.05]$. Thus no effect due to the greater stimulus exposure time of Group 1 was noted, when pronouncing aloud was required for both groups. Experiment 2 was run in order to determine the effect of amount of stimulus exposure time when Ss are allowed to use their own learning strategy, i.e., are not given pronouncing instructions.

\section{EXPERIMENT 2}

Subjects

Forty Ss were assigned at random to form two equal groups. Ss were drawn from the same population and had the same qualification as those used in Experiment 1.

Apparatus and Materials

The stimulus materials and apparatus were identical to those of Experiment 1.

\section{Procedure}

The procedure was identical to that of Experiment 1 except for a small omission in the instructions. The Ss were told nothing about a requirement to pronounce the syllables aloud.

\section{Results}

The Ss who received each stimulus visually for $15 \mathrm{sec}$ formed Group 3. Group 4 was composed of Ss who received each stimulus for $6 \mathrm{sec}$, followed by a blank slide for $8 \mathrm{sec}$, with an interslide interval of $1 \mathrm{sec}$.

Donald W. Taylor became Dean of the Graduate School, Yale University, on July 1. Formerly he was Director of the Institute of Social Science and Chairman of the Department of Psychology, Yale University.

Katherine E. Baker has left State University College at Buffalo to become Professor of Psychology, Hood College, Frederick, Maryland

S. Joyce Brotsky returns to San Fernando Valley State College as Associate Professor of Psychology after a recent leave of $a b$ sence, supported by an NIH Career Development Research Fellowship in Harvard University's Department of Social Relations.
The data for these groups and the data from Experiment 1 are presented in Table 1 .

The mean number of stimuli recalled for Group 4 was 10.45 and for Group 3 was 8.10. The difference between these means is significant $[t(1,38)=2.12, p<.05]$. Thus, the group which received the stimuli visually only $40 \%$ as long as the other group, learned significantly more. A comparison of the data from Experiment 1 and Experiment 2 revealed only one significant difference. Group 4 also learned more than Group 2 $[t(1,38)=2.60, p<.05]$.

\section{DISCUSSION}

The major findings of the two experiments are in good agreement with the position of Mechanic \& D'Andrea (1966) in regard to the importance of the visual response. Experiment 1 supported their contention that if pronouncing responses are equated across groups, the amount of visual responding is not critical. The results of Experiment 2 may even go further in illustrating the limited role of visual responses.

The fact that Ss, who looked at a blank screen for a longer time than at the stimulus, did better is an interesting finding. Although it is not clear why this occurred, one explanation seems plausible. The first experiment showed that it is possible to keep pronouncing the syllables when they are no longer being shown on the screen. However, when Ss do this, their learning is no better than Ss who are also making the pronouncing responses with the stimuli being shown all the while. So it must be the case that Ss in Experiment 2 with the 6-sec stimulus exposure made other than visual and pronouncing responses for part of the time. The work of Bugelski (1962) indicated that a powerful method for learning new material involves associating it with previously learned responses. It seems likely that Ss with no overt pronouncing requirement and no visual prompting for

\section{NOTES \& NEWS}

Donn Byrne, formerly Professor of Psychology at The University of Texas, Austin, will become Professor of Psychology at Purdue University in September 1969.

Peter D. McCormack, Professor of Psychology, Carleton University, Ottawa, Canada, will spend the $1969-70$ academic year on sabbatical at the Human Performance Center of the University of Michigan

Robert H. Pollack, formerly Deputy Director of Research, Institute for Juvenile Research, joined the faculty of the University of Georgia in April, 1969, as Professor of Psychology. either visual or overt pronouncing responses, are more free to make such associations. It is being suggested, then, that Group 4 did best because some of those Ss used associational processes more than Ss in the other groups. The postexperimental interview supports the contention that Ss do use associational processes. The projected stimulus may be considered a prompt which elicits visual and pronouncing responses, whereas a blank screen may allow for more effective learning strategies to emerge.

There is one apparent conflict between the present data and that of Mechanic (1964). He found that Ss given intentional instructions but no overt pronouncing requirement did better than Ss given an overt pronouncing requirement. For the corresponding groups in this study, Groups 1 and 3 , no significant difference was observed. This inability to replicate results further emphasizes the need to monitor or measure S's behavior during learning in order to rule out uncontrolled sources of variance. When S's behavior is monitored, it has been shown that neither type of instructions nor exposure time of the stimulus affects learning. Of course, a certain minimum exposure of the stimulus is necessary in order to evoke the response systems of $S$.

\section{REFERENCES}

BUGELSKI, B. R. Presentation time, total time, and mediation in paired-associate learning. Journal of Experimental Psychology, 1962, 63, 409-412.

HILGARD, E. R. Methods and procedures in the study of learning. In S. S. Stevens (Ed.), Handbook of experimental psychology. New York: Wiley, 1951.Pp. 517-567.

MECHANIC, A. The responses involved in the rote learning of verbal materials. Joumal of Verbal Learning \& Verbal Behavior, 1964, 3, 30-36.

MECHANIC, A., \& D'ANDREA, J. Visual and pronouncing responses, and the relation between orienting task and presentations in incidental learnings. Journal of Experimental Psychology, 1966, 71, 343-349.

An undergraduate major, leading to the BA or BS in Animal Behavior has been announced by Bucknell University. The program is an interdisciplinary curriculum offered by the departments of biology and psychology. The basic curriculum includes work in organic chemistry, biochemistry, embryology, animal physiology, ecology and evolution, animal behavior, physiological psychology, and learning and conditioning. Because the University operates on a "4-1-4" semester plan, students are free during January for field or additional laboratory work. The Chairman of the interdisciplinary committee administering the program is Professor Douglas $K$. Candland. 